\title{
REVIEW
}

\section{The ADMIT series - Issues in Inhalation Therapy. 5) Inhaler selection in children with asthma}

\section{*Søren Pedersen a, Jean Christophe Dubus ${ }^{\mathrm{b}}$, Graham Cromptonc, on behalf of the ADMIT Working Group ${ }^{d}$}

\author{
a Pediatric Research Unit, University of Southern Denmark, Kolding Hospital, Dk6000, Kolding, Denmark \\ ${ }^{b}$ Department of Pediatric Pulmonology, University Hospital of La Timone, 13385 Marseille Cedex5, France \\ 4 Midmar Drive, Edinburgh, EH10 6BU \\ ${ }^{d}$ Members of the Aerosol Drug Management Improvement Team (ADMIT): Peter J Barnes, London, UK; Mariëlle Broeders, Nijmegen, \\ The Netherlands; Chris Corrigan, London, UK; Lorenzo Corbetta, Firenze, Italy; Richard Dekhuijzen, Nijmegen, The Netherlands; \\ Jean Christophe Dubus, Marseille, France; Thomas Hausen, Essen, Germany; Meinhard Kneussl, Vienna, Austria; Federico Lavorini, \\ Firenze, Italy; Mark L Levy, Edinburgh, UK; Søren Pedersen, Kolding, Denmark; Antonio Ramalho de Almeida, Porto, Portugal; \\ Joaquin Sanchis, Barcelona, Spain; Jose L. Viejo, Hospital General Yagüe de Burgos, Spain; Walter Vincken, Brussels, Belgium; \\ Thomas Voshaar, Moers, Germany.
}

Received 6th May 2010; accepted 12th May 2010; online 18th July 2010

\begin{abstract}
Many children with asthma do not use their inhalers correctly and consequently gain little or no therapeutic benefit from the treatment. The focus of inhalation therapy should be on those inhalers which are easiest to use correctly by various groups of children and the amount of tuition and training required to obtain a correct technique. It is recommended that clinicians focus on a limited number of inhalers. Most children can be taught effective inhalation therapy by using a pMDI, a pMDI with a spacer ,or a DPI.

Most preschool children can be taught effective use of a pMDI and spacer with a valve system and a face mask. Therefore, this is the preferred mode of delivery in these age groups. When the child is capable of using the spacer without a face mask this administration technique should be adopted.

In older children pMDIs are more difficult to use correctly than a pMDI with a spacer, a DPI ,or a breath-actuated pMDI. Because DPIs and breath-actuated pMDIs are more convenient to use these devices are normally considered the preferred inhalation devices in these age groups except for administration of beclometasone dipropionate, which for safety reasons should be delivered by a spacer.

(C) 2010 Primary Care Respiratory Society UK. All rights reserved.

S Pedersen et al. Prim Care Resp J 2010; 19(3): 209-216

doi:10.4104/pcrj.2010.00043
\end{abstract}

Keywords Inhalation therapy, children, asthma, inhalation technique, inhaler selection

\section{Contents}

Introduction

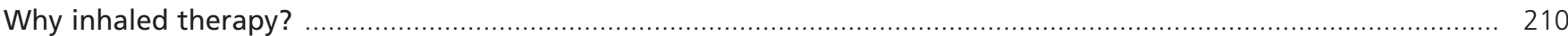

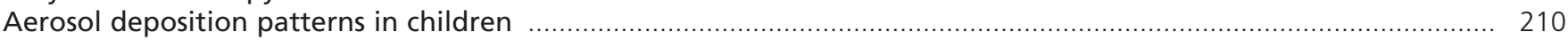

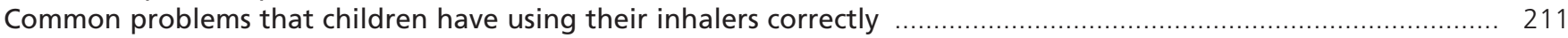

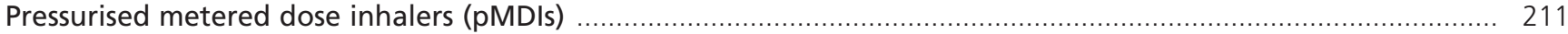

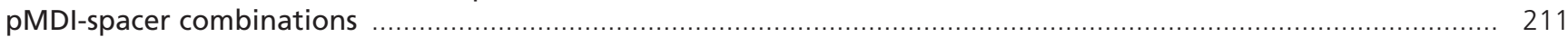

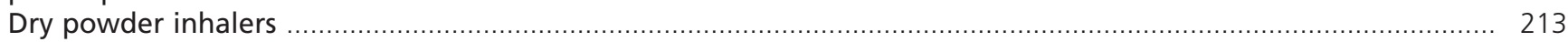

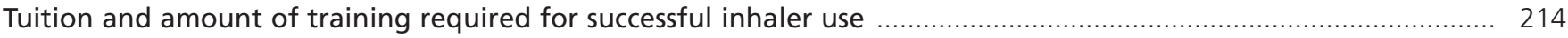

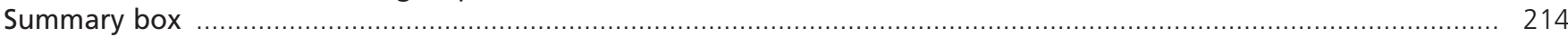

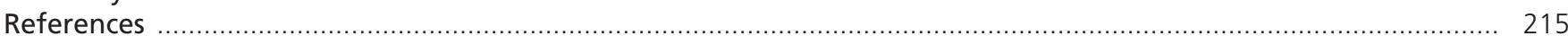

* Corresponding author: Professor Søren Pedersen, Pediatric Research Unit, Kolding Hospital, Skovvangen 2- 8, Kolding, 6000, Denmark Tel: +45 76362223 Fax: +45 76363479 E-mail: spconsult@post1.tele.dk 


\section{Introduction}

More than 100 different inhaler/drug combinations are now available for the treatment of asthma. Although such a variety increases the likelihood of finding an appropriate inhaler for each individual patient, it also increases the complexity of inhaler choice for clinicians and it may also reduce the physician's or nurse's experience with each individual inhaler. Therefore, it may be better for the individual clinician to focus on a limited number of inhalers to get better experience with the devices used.

The following three inhalation systems constitute the cornerstone of inhalation therapy in children with asthma (nebulisers are only needed in a few patients and are therefore not discussed here):

- Conventional pressurised metered-dose inhalers (pMDI)

- pMDI with a spacer attached

- Dry powder inhalers (DPI)

These three inhaler systems differ with respect to construction, aerosol cloud generation, optimal inhalation technique and ease of use. Still, with appropriate tuition and training, virtually all paediatric patients - including children less than 1 year old - can be taught effective inhaler use with one of these three systems. The precondition for this is accurate knowledge about the nature and magnitude of the problems that children of various age groups experience when using these devices correctly.

The aims of this paper are:

- to summarise the differences in aerosol deposition between children and adults and the impact of these differences on the therapeutic ratio of the inhaled drug

- to summarise the most common problems experienced by various age groups of children in using their inhalers correctly

- to provide some guidance about the tuition and amount of training required to ensure successful inhalation therapy in children with the various devices, and

- to provide a brief and simple aid for clinical decision-making for choice of inhalers in preschool as well as school-aged children

\section{Why inhaled therapy?}

When inhaled therapy is used the administered therapeutic dose is small as compared with other routes of administration and consequently the incidence of systemic side effects is very low. This is particularly important in the case of inhaled corticosteroid (ICS) treatment. Compared with oral administration, delivery of the drug directly to the airways by inhalation has a more rapid onset of action which is advantageous when bronchodilators are used to treat acute attacks of bronchoconstriction. Also, inhalation of a $\beta_{2}$-agonist offers marked protection against exercise-induced asthma which is common in children. In contrast oral administration of high doses of the same drug has no or only a marginally protective effect against this condition.' For these reasons inhalation therapy constitutes the cornerstone of asthma management in children of all ages, and several randomised controlled trials (RCTs) have demonstrated the superiority of inhaled asthma treatment over orally administered treatment.

The majority of information about the various inhalers normally comes from in vitro studies measuring particle size distribution and deposition patterns in an impactor. Such information is useful for estimating in vivo deposition patterns in the airways and assessment of the therapeutic ratio for the inhaled drug. However, the clinical importance of small, but statistically significant, differences in these parameters for the daily treatment of asthma is not well known. The prediction is not straightforward since one particle with a mass median diameter (MMAD) of $4 \mu \mathrm{m}$ will contain 16 times more drug than a particle with a MMAD of $1 \mu \mathrm{m} .{ }^{2,3}$ Furthermore, an inhaler with excellent in vitro characteristics may be clinically less effective than an inhaler with poorer output characteristics which is easier for the patient to use. Since guidelines recommend titration of the ICS dose to the lowest dose which controls the disease, small differences in lung deposition may not be so important in daily clinical practice. ${ }^{4}$ In agreement with this the available literature suggests that there is minimal difference in clinical efficacy between devices - assuming they are used correctly. ${ }^{4}$ In contrast, several studies have demonstrated that large numbers of patients do not use their inhalers correctly and consequently gain little or no therapeutic benefit from the prescribed treatment. ${ }^{5-12}$ Therefore, the focus of inhalation therapy should probably be redirected from a main emphasis on in vitro characterisation to assessments of which inhalers are easiest to use correctly by various groups of patients. Due to the heterogeneity of patients no single inhaler will satisfy the needs of all. This is particularly true for children where different age groups possess different psychomotor skills.

\section{Aerosol deposition patterns in children}

In general, the larger the particles of an aerosol and the higher the velocity, the greater is the deposition in the oropharynx and larynx. In adults deposition in the intrapulmonary airways is greatest for particles with a MMAD between 1 and $5 \mu \mathrm{m} .{ }^{13,14}$ Most particles greater than $6 \mu \mathrm{m}$ in diameter will impact above the level of the larynx and particles with a MMAD less than $1 \mu \mathrm{m}$ may not be deposited at all because they remain in suspension and are exhaled.

The optimal particle size distribution of an aerosol for effective lung deposition and therapy in children is not known. Impactor studies with inlets mimicking a cast of a young child's upper airways suggest that a small particle size may be even more important for children than for adults. ${ }^{15}$ Due to the smaller upper airway dimensions in children, a much larger proportion of 
the inhaled drug is deposited in the oropharyngeal region than in adults (for some inhalers this increased proportion is $>5$-fold). ${ }^{16}$ This can be clinically important if the corticosteroid used has a high systemic absorption of drug deposited in the oropharyngeal region (such as beclometasone dipropionate or triamcinalone where around $50 \%$ of orally deposited drug becomes systemically available ${ }^{17}$ ). Thus a typical deposition pattern of 200 mcg beclometasone in a 7-year old child delivered from a pMDI or a DPI will be around $160 \mathrm{mcg}$ deposited in the oropharynx and around $10 \mathrm{mcg}$ in the intrapulmonary airways. In such a case the total systemic availability of drug will be: $50 \%$ of $160 \mathrm{mcg}$ from the oropharynx $+10 \mathrm{mcg}$ from the lungs $=70 \mathrm{mcg}$. If a pMDI with spacer had been used around $20 \mathrm{mcg}$ beclometasone would have been deposited in the lungs and $20 \mathrm{mcg}$ in the mouth, ${ }^{17}$ resulting in a total systemic exposure of $30 \mathrm{mcg}$ even though lung deposition was higher. These considerations are even more important in young children because lung deposition decreases and oropharyngeal deposition increases with decreasing age. Typically lung deposition from the same pMDIspacer combination could be $1-2 \%$ in infants, $4-6 \%$ in children aged 2-6 years and $12 \%$ in a 10-year old child. ${ }^{17-21}$ This is also one of the reasons why young children often need almost the same inhaled dose as older children to obtain the desired clinical effect.

For corticosteroids such as ciclesonide, fluticasone propionate or fumarate, and mometasone fumarate, with a high first pass metabolism, these considerations are only important in terms of the risk of local adverse effects, which are generally milder and rarer in children than in adults. However, for beclometasone dipropionate a high oropharyngeal deposition should be avoided because it increases systemic effects without an additional increase in clinical effect. ${ }^{22-24}$ Therefore, beclometasone dipropionate should always be given by a spacer device or from a device such as the HFA-BDP Autohaler, which delivers ultrafine particles and therefore has less oropharyngeal deposition. ${ }^{17}$ However, even for the Autohaler, use of a spacer improves the therapeutic ratio of beclometasone somewhat. ${ }^{18}$

\section{Common problems that children have in using their inhalers correctly Pressurised metered dose inhalers (pMDIs)}

In pressurised aerosols the active drug is dispersed in suspension or as a solution in a small canister. Previously, chlorofluorocarbon (Freon) was the preferred propellant, but this is increasingly being replaced by hydrofluoroalkane-134a (HFA). The patient actuates a dose of aerosol by pressing down the canister into the actuator seating. This releases a metered volume of drug, propellants and surfactant through the actuator orifice into the air.

Pressurised metered-dose inhalers (pMDIs) contain multiple doses of the drug and, except for breath-actuated devices, do not have to be reloaded before each inhalation. The canister of suspension aerosols should be shaken before treatment to ensure proper filling of the metering chamber with a homogenous mixture of the contents. If the aerosol is cold due to storage in a refrigerator or in a school bag during winter the effect of some inhalers decreases because the vapor pressure of the propellants becomes too low to produce an adequate dose and sufficiently small drug particles..$^{25}$ The same may be the case for HFA inhalers which have not been used for some time, in which case the first 1-3 actuations will not deliver the prescribed drug dose..$^{25}$ Few pMDIs have a dose counter.

Although correct use of a pMDI looks simple, several studies have reported that a large proportion of adults as well as school- age children do not use these devices correctly. Most of the difficulties are related to problems with correct coordination of actuation and inhalation - either inhaling too late or too early in relation to the actuation (Table 1). 11,12,26,27 Moreover, cessation of inhalation when the aerosol particles reach the soft palate (the cold Freon effect) or actuation of the aerosol into the mouth followed by inhalation through the nose is common. ${ }^{11,28}$ Breath-holding is normally recommended after the inhalation, but the clinical importance of breath-holding has not been documented in children. In adults breath-holding only improved lung deposition after an extremely slow inhalation, ${ }^{29}$ which virtually no children do when using a pMDI.

It is estimated that more than $50 \%$ of school-age children receiving inhalation therapy with a pMDI gain reduced or no clinical benefit from the prescribed medication due to incorrect inhaler use. ${ }^{11,12}$ Due to even poorer coordination abilities in young children, and the reduced strength and dexterity of their fingers to actuate the aerosol, pMDIs should not normally be prescribed to children younger than 7 years old (Figure 1).

Use of a breath-actuated pMDI (Autohaler, EasiBreathe) will reduce the actuation inhalation coordination difficulties. The remaining problems remain, however. Studies suggest that this inhaler should mainly be reserved for children older than 6 years and that children of that age can also use it correctly during episodes of acute wheeze. ${ }^{10,30}$

\section{pMDI-spacer combinations}

Various holding chambers (spacers) may be attached to the mouthpiece of a conventional pressurised aerosol. These devices ensure that the aerosol particles have a slower velocity and a smaller particle size when they reach the patient. This is a theoretical advantage. Spacers also allow more complete evaporation of the propellants and deposition of these in the device before the inhalation. Most devices have a one-way valve that opens during inspiration and closes during expiration, which markedly eliminates the coordination problems seen with the pMDI. ${ }^{4,31,32}$ Moreover, the cold Freon effect is reduced. Therefore, spacers are easier to use than a pMDI. ${ }^{33}$ Most school-age children can learn the correct use of these devices after appropriate instruction and demonstration 
Table 1. Inhaler strategy, optimal inhalation technique and most common problems with correct inhaler use in children.

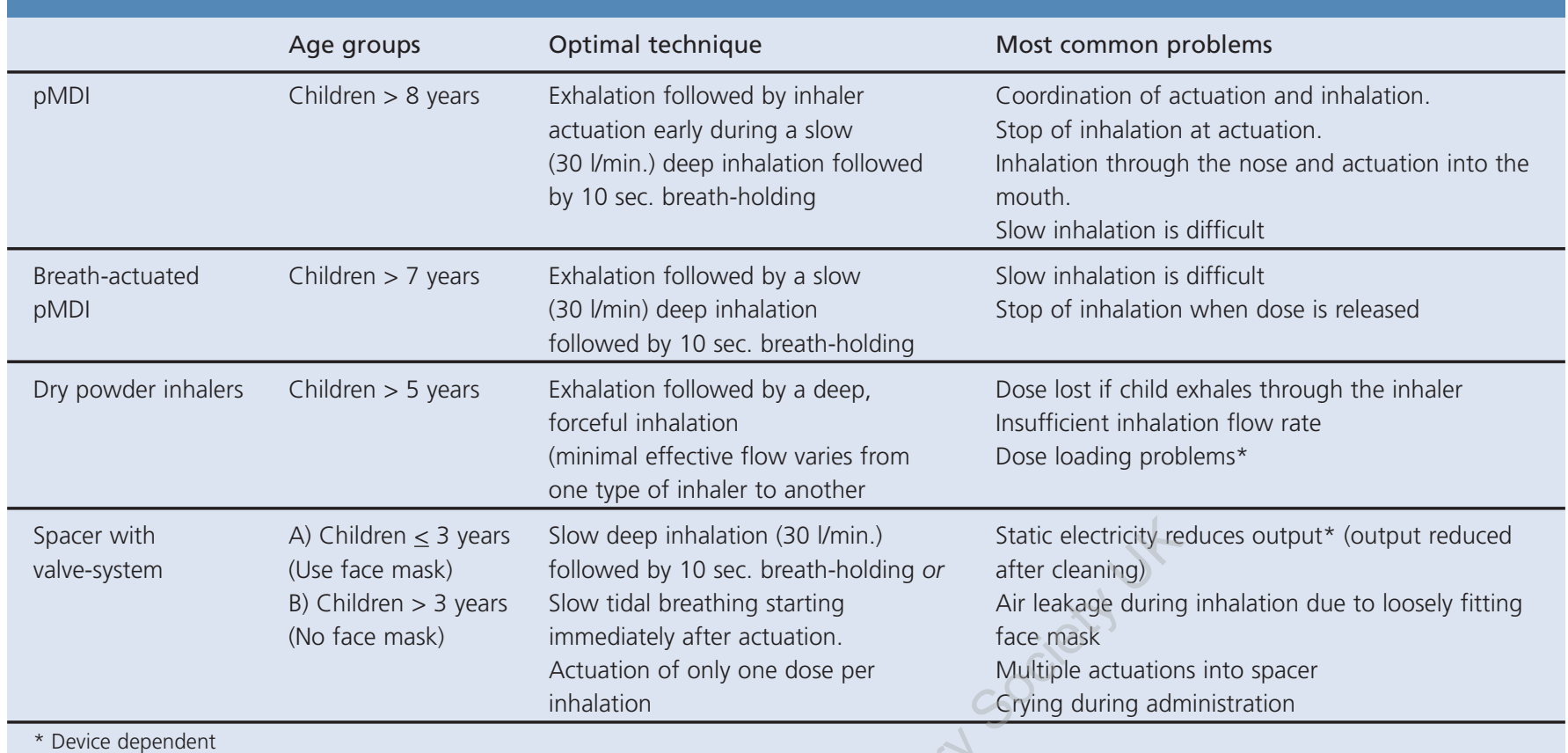

Figure 1. Proportion of children at the first author's clinic, who, after repeated, individual, personal instructions, practice at home and demonstrations of the inhalation technique by the child, demonstrated a correct inhalation technique on at least three of four demonstrations. The instructions were given by an experienced nurse. Over the years 1682 patients have been instructed according to the same plan. The number of tuitions and instructions varied from two to eight (mean 3.2). Age and the psychomotor skills of the child influenced the number of training sessions. DPI = dry powder inhaler, pMDI = pressurised metered dose inhaler (freon). The breath-actuated pMDI was a HFA pMDI.

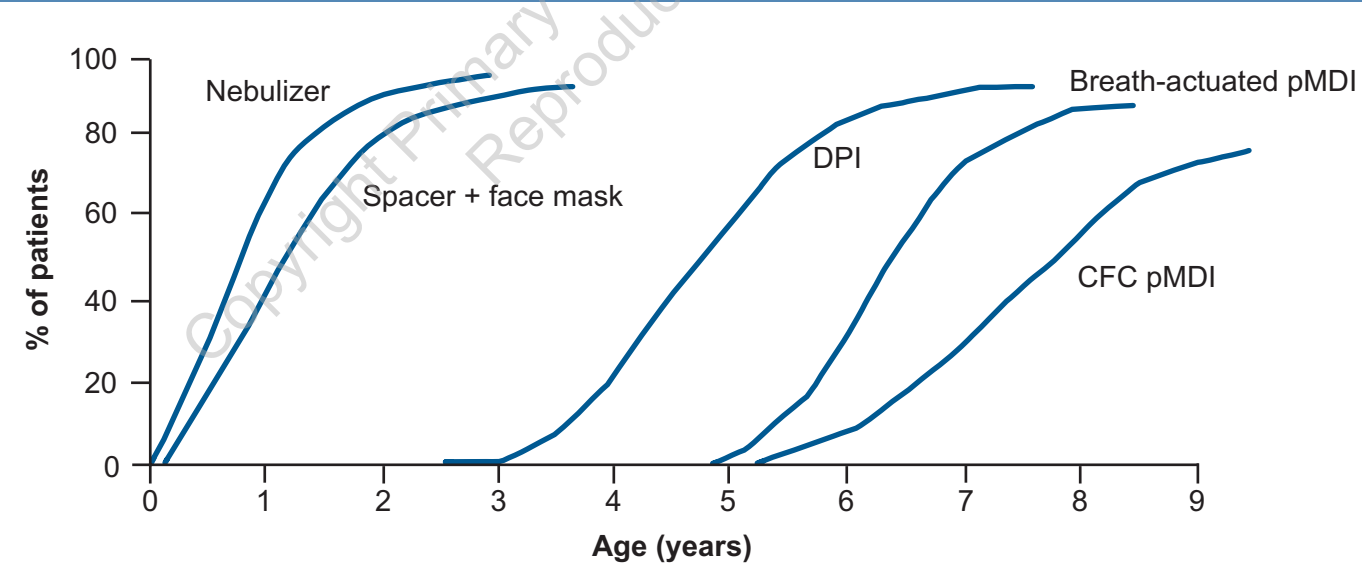

(Figure 1). Spacers can also be used for delivery of bronchodilators during attacks of acute bronchoconstriction when they are as effective as nebulisers. ${ }^{34}$

Most children younger than 6 years old can also be taught the effective use of a spacer. The younger age groups need a face mask attached to the mouthpiece because they cannot fit their lips tightly around the mouthpiece. ${ }^{32}$ Although never studied formally, young children require several more training sessions than older children before the inhalation technique is acceptable. In these age groups help from the parents is required.

The inhalation technique with spacers is simple, and quiet tidal breathing normally results in a good clinical effect. ${ }^{35}$ This inhalation technique is the only possible option in children younger than 4 years old. However, one study found that, when inhaling an extra fine particle formulation from a spacer, one deep inhalation followed by breath-holding resulted in significantly improved lung deposition compared with tidal 
breathing across all ages in children aged $4-15$ years. ${ }^{18}$ In young children the parents should ensure that the valve is moving correctly. ${ }^{32,36}$ Crying during the administration or air leakage between the face mask and the face due to a loosely fitting face mask markedly reduces the aerosol delivery to the intra-pulmonary airways (Table 1). One puff should be actuated into the spacer followed by some respiratory cycles before the next actuation. Multiple actuations into the spacer will reduce the amount of inhaled drug. This is more marked for low volume spacers. $32,3,38$

The various spacers vary in size from around $200 \mathrm{ml}$ to 750 $\mathrm{ml}$. The consensus says that (generally speaking) low volume spacers are preferable in young children, who, due to a low tidal volume, may have to use several breaths to empty a large volume spacer. ${ }^{32}$ Although it sounds plausible, this has never been formally assessed in vivo. Thus, one study found no differences between a high and low volume spacer in the amount of drug inhaled by very young children - probably because the children increased their minute ventilation once the face mask was placed over their mouth and nose. ${ }^{39} \mathrm{~A}$ low dead space of the face mask may be more important than the volume of the spacer device in young children. A high dead volume of the face mask combined with rapid, shallow breathing in a young child may substantially reduce the inhaled dose. ${ }^{32}$

The main problem with spacers is that they are bulky, inconvenient and require a certain amount of maintenance. Electrostatic charges may interfere markedly with the drug delivery from some spacer devices. ${ }^{32,40,41}$ Spacers should be washed with detergent at least every month. If the spacer device is made of a material which may become electrostatic they should be drip dried after washing to limit electrostatic charges. Spacers made of non-electric chargeable material do not require this. ${ }^{32,40}$ The valves should be replaced at least once a year or more frequently with some devices.

Spacers reduce the oropharyngeal deposition of drug substantially (from about $80 \%$ to about $30 \%$ ), yet the dose delivered to the intrapulmonary airways is often the same or even higher than that from a pMDI alone ${ }^{32}$ - though not all spacers have been thoroughly studied with respect to this.

Generally spacers have a favorable clinical effect/systemic effect ratio, though this has only been studied in school children not using a face mask. ${ }^{17}$ The majority of children younger than 4 years old can only use a spacer with a face mask attached. Most young children breathe in through the nose, which serves as an efficient filter of larger particles, and therefore may cause considerable drug deposition in the nose and a reduced deposition in the lung. ${ }^{42}$ The importance of this has not been sufficiently elucidated.

\section{Dry powder inhalers}

In DPIs, the drug is provided as a finely milled powder in reservoirs, blisters or gelatin capsules. Each blister or capsule contains only a single dose of drug substance, so it has to be replaced before each treatment. Often the active drug is mixed with carrier substance such as lactose or micronised glucose so that the material in the capsules consists of fine drug particles in large aggregates (diameter of about $60 \mu \mathrm{m}$ ), either alone or in combination with the large carrier particles. Most of the particles from DPIs are too large to penetrate into the lungs. However, the turbulent airstream created in the inhaler during inhalation causes the aggregates to break up sufficiently to be carried into the lower airways. Thus the effect of powder inhalers is dependent upon a certain minimum amount of energy from the patient's inhalation to create the correct particle size of the drug and up to a certain point increases in flow rate will increase the number of particles within the "respirable range" and the clinical effect of the inhalation. The dependency of the amount of respirable particles on changes in the inspiratory flow rate varies markedly between different DPIs. Some show little variation with increasing flow rate whereas others show marked increases in inspirable particles with increasing flow rates. . $2,43-47^{2}$

Forceful fast inhalations enhance the effect of many DPIs in children, whereas breath-holding, tilting of the head during inhalation or inhalation from functional residual capacity instead of residual volume do not seem to influence the clinical effect. ${ }^{2}$ The inhalation effort and the inhalation flow rate required to generate the optimal therapeutic aerosol vary between different DPIs. Therefore, results obtained with one inhaler cannot be used to characterise another. All DPIs require a certain minimum inspiratory flow rate to release the dose and generate a certain amount of respirable particles. In some inhalers the flow required to release the dose is lower than the flow rate needed to generate the optimal amount of particles. This involves a risk of inhaling a dose which will mainly be deposited in the mouth.

Even when used optimally, marked (up to 4-fold) variations exist between different DPIs in the amount of drug deposited in the intra-pulmonary airways in children ${ }^{48.51}$ Generally, the fraction of the inhaled dose deposited in the oropharyngeal area after inhalation from a DPI is high, but substantial differences exist between different devices (from $40 \%$ to $80 \%$ ). 48.51

DPIs are breath-actuated and therefore reduce/eliminate the problems of coordinating actuation and inhalation seen with the pMDI (Table 1). They are as convenient to carry as a pMDI but easier to use. ${ }^{52-55}$ The various DPIs also seem to differ in their ease of use. ${ }^{52-55}$ However, most studies assessing the frequency of correct inhaler use score the use by counting the numbers of errors without weighing the clinical importance of each error. Therefore, the clinical importance of small differences between different DPIs in correct inhaler use is not known. The main problem with DPIs is in training the child not to exhale through the inhaler before the inhalation, since that will blow out the dose and increase the humidity within the inhaler. 
Some DPIs are single dose inhalers and are therefore less convenient to use because they have to be loaded before each inhalation and some children have difficulties doing this (i.e. this is device dependent). Some reservoir inhalers such as the Turbuhaler must be loaded in the upright position; otherwise the metered dose will be reduced when less than half the number of doses is left in the powder reservoir.

The requirement of a rapid forceful inhalation and no exhalation through the inhaler for a good effect of a DPI limits the number of children younger than 6 years old who can consistently use a DPI correctly. Some children aged 5 can be taught to use a DPI after repeated tuition, demonstration and training at home. However, even after such measures the majority of children younger than 5 years of age cannot consistently use a DPI correctly. ${ }^{56}$ Therefore, DPIs should preferably be reserved for children older than 5 years (Figure 1).

Storage of the powder at high humidity may dissolve the drug or influence inter-particulate bonding in some devices so that large agglomerates are formed, which are not easily dispersed into sufficiently fine particles by the inhalation. ${ }^{57,58}$ The same phenomenon may also be seen in some devices if the patient by mistake exhales through the inhaler after the dose has been loaded.

\section{Tuition and amount of training required for successful inhaler use}

Initial tuition and training as well as repeated follow-ups are crucial for correct inhaler use in children. Prescription of inhaled therapy to a child should always be accompanied by thorough tuition of correct inhaler use followed by the child's repeated demonstration of the inhalation technique. Pamphlets and videos may be helpful, ${ }^{66}$ but they cannot stand alone - individual, personal instruction and repeated demonstration of the inhalation technique by the child are necessary. The number of corrections and demonstrations of technique depend on age and the psychomotor skills of the child. After three instructions and demonstrations $98 \%$ and $92 \%$ of 6-11 year old children demonstrated a correct technique using a pMDI spacer or DPI. After two repetitions the corresponding figures were $90 \%$ (spacer) and $76 \%$ (DPI). ${ }^{5}$ These results seemed independent of whether a pediatrician or a trained nurse gave the instructions.

No studies have formerly assessed the amount of repetitions required in pre-school children, but it is likely to be higher than three. One study assessed the use of a DPI (Turbuhaler) in children aged 3-6 years; the conclusion was that even after repeated instructions and three weeks with daily practising at home with electronic training device only children aged 5 could use the inhaler correctly most of the time..$^{56}$

A correct inhalation technique is often lost over time, and therefore inhalation instructions should be given repeatedly to

\section{SUMMARY BOX}

\section{Inhaler strategy in different age groups of children}

Based on current knowledge, a rational inhaler strategy in children can be summarised as follows:

Children $\leq 5$ years: pMDIs or DPIs should not normally be used in these age groups. Some children aged 5 can be taught to use a DPI provided repeated tuition, demonstration and control is given. The vast majority of children younger than 6 years can be taught effective use of a pMDI and spacer with a valve system and a face mask for daily delivery of maintenance treatment as well as for treatment of acute episodes of wheeze with $\beta_{2}-$ agonists. Spacers are as effective as nebulisers both for daily treatment and during acute episodes of wheeze. Since spacers are more convenient, cheaper and require less maintenance, they are the preferred device in these age groups. When the child is capable of using the spacer without a face mask effectively this administration technique should be adopted.

Children $>5$ years: In these age groups pMDls seem to be more difficult to use correctly than a pMDI with a spacer, a DPI or a breath-actuated pMDI. Because DPIs and breath-actuated pMDIs are more convenient to use than a pMDI with a spacer these devices are often considered the preferred inhalation devices except for administration of beclometasone propionate, which should always be given by a spacer device. A pMDI with a spacer, a DPI, or a breath-actuated pMDI can all be used effectively during episodes of acute wheeze.

With this approach children can be taught effective inhaler use with a minimum of instructional time. Finally, it must be remembered always to consider the child's wishes since prescription of an inhaler which the physician but not the child likes is likely to reduce compliance.

achieve and maintain correct inhalation technique in asthmatic children. Patients should demonstrate their inhalation technique, and relevant instructions and corrections should be provided, at every visit and/or regularly at prescription renewals. This will reduce the deterioration in inhalation technique with time, irrespective of the type of inhaler used.

Children who have initially received comprehensive inhalation instructions with repeated checks of proper inhalation technique at the pharmacy or in a clinical trial setting are also more likely to maintain a correct inhalation technique than children who have only received a single instruction. ${ }^{7,33}$

Follow-up of asthma patients and repeated inhalation instruction is time-consuming. However, the clinical results will be better and one trial suggested that the improvements were achieved at a lower daily dose of inhaled corticosteroid. ${ }^{59}$ The main reason for this seemed to be that the frequency of a correct inhalation technique increased from $64 \%$ to $95 \%$ during the one-year study period. 


\section{Conflict of interest declaration}

$S$ Pedersen has given talks for Nycomed, GlaxoSmithKline (GSK) and Meda AB and acted as a consultant for Nycomed and AstraZeneca. JC Dubus has been on expert boards for MEDA, Novartis, and MSD and received research grants from Chiesi, Roche, GSK and AstraZeneca. G Crompton has given talks and acted as a consultant for MEDA AB. Conflicts of interest for all ADMIT members are listed at the end of the first paper in this series - see Dekhuijzen et al., Prim Care Resp J 2007;16(6): 341-8.

\section{References}

1. Fuglsang G, Hertz B, Holm B. No protection by oral terbutaline against exerciseinduced asthma in children: a dose response study. Eur Respir J 1993;6:527-30.

2. Newhouse MT, Ruffin RE. Deposition and fate of aerosolized drugs. Chest 1978;73(6 Suppl):936-43.

3. Dolovich M, Ruffin RE, Roberts R, Newhouse MT. Optimal delivery of aerosols from metered dose inhalers. Chest 1981;80(6 Suppl):911-15.

4. Dolovich MB, Ahrens RC, Hess DR, et al. Device selection and outcomes of aerosol therapy: Evidence-based guidelines: American College of Chest Physicians/American College of Asthma, Allergy, and Immunology. Chest 2005;127(1):335-71. http://dx.doi.org/10.1378/chest.127.1.335

5. Brand PL. Key issues in inhalation therapy in children. Curr Med Res Opin 2005;21 Suppl 4:S27-32. http://dx.doi.org/10.1185/030079905X61767

6. Everard ML. Guidelines for devices and choices. J Aerosol Med 2001;14 Suppl 1:S59-64. http://dx.doi.org/10.1089/08942680150506358

7. Kamps AW, van EB, Roorda RJ, Brand PL. Poor inhalation technique, even after inhalation instructions, in children with asthma. Pediatr Pulmonol 2000;29(1):39-42. http://dx.doi.org/10.1002/(SICI)1099-0496(200001)29: 1<39::AID-PPUL7>3.3.CO;2-7

8. Gracia-Antequera M, Morales Suarez-Varela M. An intervention to improve the inhalatory technique of children and adolescents with asthma. Allergol Immunopathol (Madr) 1999;27(5):255-60.

9. De BK, Alifier M, Warnier G. Is the correct use of a dry powder inhaler (Turbohaler) age dependent? J Allergy Clin Immunol 1999;103(5 Pt 1):763-7.

10. Pedersen S, Mortensen S. Use of different inhalation devices in children. Lung 1990;168 Suppl:653-7. http://dx.doi.org/10.1007/BF02718190

11. Pedersen S, Frost $L$, Arnfred T. Errors in inhalation thechnique and efficacy of inhaler use in asthmatic children. Allergy 1986;41:118-24. http://dx.doi.org/ 10.1111/j.1398-9995.1986.tb00287.x

12. Pedersen S. Inhaler use in children with asthma. Danish Med Bull 1987;34:234 49.

13. Newman S, Pavia D, Morén F, Sheahan NF, Clarke SW. Deposition of pressurized aerosols in the human respiratory tracts. Thorax 1981;36:52-5. http://dx.doi.org/10.1136/thx.36.1.52

14. Dolovich M, Coates G, Hargreave F, Newhouse MT. Aerosols in diagnosis: ventilation, airway penetrance, aireay reactivity, epithelial permeability and mucociliary transport. In: Moren F, Newhouse MT, Dolovich M, editors. Aerosols in Medicine. Principles, Diagnosis, and Therapy. Amsterdam: Elsevier Science Publishers; 1985. p. 225-59.

15. Olsson B, Borgström L, Asking L, Bondesson E. Effect of inlet throat on the correlation between measured fine particles dose and lung deposition. 1996;In Dalby R, Byron P, Farr S, eds. Respiratory Drug Delivery V Buffalo Grove, IL: Interpharm Press, 1996:273-81.

16. Agertoft L, Andersen A, Weibull E, Pedersen S. Systemic availability and pharmacokinetics of nebulized budesonide in pre-school children with asthma. Arch Dis Child 1999;80:241-7. http://dx.doi.org/10.1136/adc.80.3.241

17. Agertoft L, Pedersen S, Harrison L. Lung deposition and basic pharmacokinetic parameters of beclomethasone dipropionate in asthmatic children after inhalation from a HFA-pMDI (Autohaler) and a CFC-pMDI with spacer. Am J Respir Crit Care Med 1999;159(No 3 Pt 2):A120.

18. Roller CM, Zhang G, Troedson RG, Leach CL, Le Souef PN, Devadason SG.
Spacer inhalation technique and deposition of extrafine aerosol in asthmatic children. Eur Respir J 2007;29(2):299-306. http://dx.doi.org/10.1183/ 09031936.00051106

19. Wildhaber JH, Devadason SG, Wilson JM, et al. Lung deposition of budesonide from turbuhaler in asthmatic children. Eur J Pediatr 1998;157(12):1017-22. http://dx.doi.org/10.1007/s004310050990

20. Devadason SG, Everard ML, MacEarlan C, et al. Lung deposition from the Turbuhaler in children with cystic fibrosis. Eur Respir J 1997;10(9):2023-8.

21. Wildhaber JH, Janssens HM, Pierart F, Dore ND, Devadason SG, LeSouef PN. High-percentage lung delivery in children from detergent-treated spacers. Pediatr Pulmonol 2000;29(5):389-93. http://dx.doi.org/10.1002/(SICI)10990496(200005)29:5<389::AID-PPUL8>3.0.CO;2-3

22. Prahl $P$, Jensen $T$. Decreased adrenocortical suppression utilizing the Nebuhaler for inhalation of steroid aerosols. Clin Allergy 1987;17:393-8. http://dx.doi.org/10.1111/j.1365-2222.1987.tb02031.x

23. Brown $\mathrm{PH}$, Blundell G, Greening $A P$, Crompton GK. Do large volume spacer devices reduce the systemic effects of high dose inhaled corticosteroids? Thorax 1990;45:736-9. http://dx.doi.org/10.1136/thx.45.10.736

24. Selroos $O$, Halme M. Effect of a volumatic spacer and mouth-rinsing on systemic absorption of inhaled corticosteroids from a metered dose inhaler and a dry powder inhaler. Thorax 1991;46:891-4. http://dx.doi.org/ 10.1136/thx.46.12.891

25. Hendeles L, Colice GL, Meyer RJ. Withdrawal of albuterol inhalers containing chlorofluorocarbon propellants. N Engl J Med 2007;356(13):1344-51. http://dx.doi.org/10.1056/NEJMra050380

26. Fink $J B$, Rubin BK. Problems with inhaler use: a call for improved clinician and patient education. Respir Care 2005;50(10):1360-74.

27. Rubin BK, Fink JB. Optimizing aerosol delivery by pressurized metered-dose inhalers. Respir Care 2005;50(9):1191-200.

28. Pedersen $S, \varnothing$ stergaard P. Nasal inhalation as a cause of inefficient pulmonary aerosol inhalation thechnique in children. Allergy 1983;38:191-4. http://dx.doi.org/10.1111/j.1398-9995.1983.tb01605.x

29. Newman SP, Pavia D, Clarke SW. How should a pressurized beta-adrenergic bronchodilator be inhaled? Eur J Respir Dis 1981;62(1):3-21.

30. Ruggins NR, Milner AD, Swarbrick A. An assessment of a new breath actuated inhaler device in acutely wheezy children. Arch Dis Child 1993;68:477-80. http://dx.doi.org/10.1136/adc.68.4.477

31. Fink JB, Rubin BK. Problems with inhaler use: a call for improved clinician and patient education. Respir Care 2005;50(10):1360-74.

32. Mitchell JP, Nagel MW. Valved holding chambers (VHCs) for use with pressurised metered-dose inhalers (pMDIs): a review of causes of inconsistent medication delivery. Prim Care Resp J 2007;16(4):207-14. http://dx.doi.org/ 10.3132/pcrj.2007.00034

33. Kamps AW, Brand PL, Roorda RJ. Determinants of correct inhalation technique in children attending a hospital-based asthma clinic. Acta Paediatr 2002;91(2):159-63. http://dx.doi.org/10.1080/080352502317285144

34. Castro-Rodriguez JA, Rodrigo GJ. Beta-agonists through metered-dose inhaler with valved holding chamber versus nebulizer for acute exacerbation of wheezing or asthma in children under 5 years of age: a systematic review with meta-analysis. J Pediatr 2004;145(2):172-7. http://dx.doi.org/10.1016/ j.jpeds.2004.04.007

35. Gleeson JG, Price J. Nebuhaler technique. Br J Dis Chest 1988;82:172-4. http://dx.doi.org/10.1016/0007-0971(88)90039-3

36. Crompton GK, Barnes PJ, Broeders M, et al. The need to improve inhalation technique in Europe: a report from the Aerosol Drug Management Improvement Team. Respir Med 2006;100(9):1479-94. http://dx.doi.org/ 10.1016/j.rmed.2006.01.008

37. Newman S, Millar A, Lennard-Jones T, Moren F, Clarke SW. Improvement of pressurised aerosol deposition with nebuhaler spacer device. Thorax 1984;39:935-41. http://dx.doi.org/10.1136/thx.39.12.935 
38. Clark AR, Rachelefsky G, Mason PL, Goldenhersh MJ, Hollingworth A. The use of reservoir devices for the simultaneous delivery of two metered-dose aerosols. J Allergy Clin Immunol 1990;85:75-9.

39. Agertoft $L$, Pedersen S. Influence of spacer device on drug delivery to young children with asthma. Arch Dis Child 1994;71:217-20. http://dx.doi.org/ 10.1136/adc.71.3.217

40. Mitchell JP, Coppolo DP, Nagel MW. Electrostatics and inhaled medications: influence on delivery via pressurized metered-dose inhalers and add-on devices. Respir Care 2007;52(3):283-300.

41. Janssens HM, Devadason SG, Hop WC, LeSouef PN, de Jongste JC, Tiddens HA. Variability of aerosol delivery via spacer devices in young asthmatic children in daily life. Eur Respir J 1999;13(4):787-91.

42. Köhler D, Fleicher W. Established facts of inhalation therapy: a review of aerosol therapy and commonly used drugs. Lung \& Respiratory 1989;6:1-16.

43. Richards R, Dickson CR, Renwick AG, Lewis RA, Holgate S. Absorption and disposition kinetics of cromolyn sodium and the influence of inhalation technique. J Pharmacol Exp Ther 1987;241(3):1028-32.

44. Prime D, Grant AC, Slater AL, Woodhouse RN. A critical comparison of the dose delivery characteristics of four alternative inhalation devices delivering salbutamol: pressurized metered dose inhaler, Diskus inhaler, Diskhaler inhaler, and Turbuhaler inhaler. J Aerosol Med 1999;12(2):75-84. http://dx.doi.org/ 10.1089/jam.1999.12.75

45. Nielsen KG, Skov M, Klug B, Ifversen M, Bisgaard H. Flow-dependent effect of formoterol dry-powder inhaled from the Aerolizer. Eur Respir J 1997;10:2105-09.

46. Olsson B. Aerosol particle generation from dry powder inhalers: can they equal pressurized metered dose inhalers? J Aerosol Med 1995;8 (suppl 3):13-9. http://dx.doi.org/10.1089/jam.1995.8.Suppl_3.S-13

47. Olsson B, Asking L. Critical aspects of the function of inspiratory flow driven inhalers. J Aerosol Med 1994;7(Suppl 1):S43-7. http://dx.doi.org/10.1089/ jam.1994.7.Suppl_1.S-43

48. Martin RJ, Szefler SJ, Chinchilli VM, et al. Systemic effect comparisons of six inhaled corticosteroid preparations. Am J Respir Crit Care Med 2002;165(10):1377-83. http://dx.doi.org/10.1164/rccm.2105013

49. Agertoft $L$, Pedersen $S$. Lung deposition and systemic availability of fluticasone Diskus and budesonide Turbuhaler in children. Am J Respir Crit Care Med
2003;168(7):779-82. http://dx.doi.org/10.1164/rccm.200302-2000C

50. Zainudin BMZ, Biddiscombe M, Tolfree SEJ, Short M, Spiro SG. Comparison of bronchodilator responses and deposition patterns of salbutamol inhaled from a pressurised metered dose inhaler, as a dry powder, and as nebulised solution. Thorax 1990;45:469-73. http://dx.doi.org/10.1136/thx.45.6.469

51. Biddiscombe M, Marriott RJ, Melchor R, Short M, Spiro SG, Taylor AJ. The preparation and evaluation of pressurized metered dose and dry powder inhalers containing 99mTc labelled salbutamol. J Aer Med 1991;4 (suppl 1):912.

52. Khassawneh BY, Al-Ali MK, Alzoubi KH, et al. Handling of inhaler devices in actual pulmonary practice: metered-dose inhaler versus dry powder inhalers. Respir Care 2008;53(3):324-8.

53. Wieshammer S, Dreyhaupt J. Dry powder inhalers: which factors determine the frequency of handling errors? Respiration 2008;75(1):18-25. http://dx.doi.org/ 10.1159/000109374

54. Malot L, Molimard M, Abouelfatah A, et al. [Assessment of the handling of inhaler devices: an observational study of children in primary care]. Arch Pediatr 2007;14(10):1190-5. http://dx.doi.org/10.1016/j.arcped.2007.06.017

55. Molimard M. How to achieve good compliance and adherence with inhalation therapy. Curr Med Res Opin 2005;21 Suppl 4:S33-7. http://dx.doi.org/ 10.1185/030079905X61776

56. Agertoft L, Pedersen S. Importance of training for correct Turbuhaler use in preschool children. Acta Pædiatr Scand 1998;87:842-7. http://dx.doi.org/ 10.1080/080352598750013608

57. Young PM, Price R, Tobyn MJ, Buttrum M, Dey F. Investigation into the effect of humidity on drug-drug interactions using the atomic force microscope. J Pharm Sci 2003;92(4):815-22. http://dx.doi.org/10.1002/jps.10250

58. Price $R$, Young PM, Edge $S$, Staniforth JN. The influence of relative humidity on particulate interactions in carrier-based dry powder inhaler formulations. Int $J$ Pharm 2002;246(1-2):47-59. http://dx.doi.org/10.1016/S0378-5173(02)00359-9

59. Kamps AW, Brand PL, Kimpen JL, et al. Outpatient management of childhood asthma by paediatrician or asthma nurse: randomised controlled study with one year follow up. Thorax 2003;58(11):968-73. http://dx.doi.org/10.1136/ thorax.58.11.968

\section{Available online at http://www.thepcrj.org}

